\title{
Medical Treatment of Rheumatoid Arthritis: A Review
}

AHM FEROZ

(J Bangladesh Coll Phys Surg 2010; 28: 30-39)

\section{Introduction:}

Rheumatoid arthritis is a chronic systemic inflammatory disease whose major manifestation is synovitis of multiple joints. The hallmark of rheumatoid arthritis is symmetrical synovial proliferation and tenderness of multiple joints, particularly the small joints of hands and feet. When the disease is unchecked, it leads to substantial disability and premature death ${ }^{1}$. It affects approximately 0.8 percent of adults worldwide ${ }^{2}$ and is more common in women (by a ratio of 3 to 1 ) and has an earlier onset in women, frequently beginning in the childbearing years. ${ }^{3}$ Recent advances in understanding the cytokine networks that are responsible for the ongoing inflammatory response in rheumatoid arthritis ${ }^{4}$ have led to the successful use of therapies that target tumor necrosis factor $\alpha$ (TNF- $\alpha$ ) and interleukin- ${ }^{4}$. During the past 10 years, improved understanding of the pathophysiology of rheumatoid arthritis has led to several key changes in the approach to therapy. First, early diagnosis and treatment are important; second the use of disease modifying anti rheumatic drugs (DMARDs) in combination is highly effective. Third, the use of agents that target cytokines, such as (TNF- $\alpha$ ) and interleukin-1 is an effective strategy. And fourth, recognition is growing that the assessment of treatment outcomes should include an analysis of important coexisting illnesses (particularly cardiovascular disease and osteoporosis). In this article, I will discuss the clinical application of these principles, which has resulted in marked improvement in clinical outcomes.

\section{Early Diagnosis and Treatment}

Joint damage occurs early in the course of rheumatoid arthritis; 30 percent of patients have radiographic

Address of Correspondence: Dr. A.H.M. Feroz, FCPS, MD (Internal Medicine), Senior Consultant of Medicine, Department of Medicine, 200 bedded Hospital, Narayangonj

Received: 4 May, 2008

Accepted: 25 January, 2009 evidence of bony erosions at the time of diagnosis, and this proportion increases to 60 percent by two years ${ }^{5}$. Unfortunately, bony erosions and deformities are largely irreversible. Initiation of therapy with DMARDs within three months after the diagnosis of rheumatoid arthritis is crucial; a delay of as little as three months in the introduction of these medications results in substantially more radiographic damage at five years ${ }^{6}$. Therefore, early diagnosis, although challenging, is critical ${ }^{7}$. The diagnosis of rheumatoid arthritis cannot be established by a single laboratory test or procedure but is made with four or more of the diagnostic criteria ${ }^{8}$. The diagnostic criteria are the presence of morning stiffness (more than 1 hour), arthritis of three or more joint areas, arthritis of the hand joints, symmetrical arthritis, rheumatoid nodules, elevated levels of serum rheumatoid factor, radiographic changes and duration of 6 weeks or more. Many other syndromes, including self-limiting viral conditions lasting several weeks, mimic rheumatoid arthritis. Antibodies to cyclic citrulinated peptides (CCPs) appear to have a high specificity (90 to 98 percent) and thus may prove useful in early diagnosis even though the sensitivity of the test for them is approximately 50 to 60 percentages at presentation $^{9}$.Interestingly, these antibodies may appear in the serum years before the onset of clinical disease $\mathrm{e}^{10}$.

\section{Gemeral Therapeutic Principles}

Guidelines concerning therapy for rheumatoid arthritis have been published recently by the American college of Rheumatology (Fig-1) ${ }^{11}$. No treatment cures rheumatoid arthritis; therefore, the therapeutic goals are a remission of joint symptoms, a return of full function, and the maintenance of remission with DMARD therapy. A useful intermediate goal is to have all patients evaluated by a rheumatologist within three months after the onset of symptoms, So that essentially all patients will be receiving DMARDs by the time they have had symptoms for three months. 
To evaluate the success of intervention, investigators have used a number of clinical measures. They include the number of joints that are tender and swollen, markers of inflammation (including the erythrocyte sedimentation rate and c- reactive protein level), and patients' responses to questions about their pain, their global assessment of disease activity, and their physical function. The American College of Rheumatology criteria for improvement can be used by clinicians to quantify patients' improvement after treatment (Table1) ${ }^{12}$. Most clinical studies have required a benchmark of 20 percent improvement in these criteria, a result that is known as ACR 20; now that better treatments are being initiated earlier in the course of the disease, 50 percent improvement (ACR 50 ) is becoming a more frequent target.

\section{Medications}

Medications that are used to treat rheumatoid arthritis are divided into three main classes: nonsteroidal antiinflammatory drugs (NSAIDs), corticosteroids and DMARDs (both synthetic and biologic).

\section{NSAIDS}

NSAIDs are particularly helpful during the first few weeks in which a patient has symptoms, because the drugs provide partial relief of pain and stiffness until a definitive diagnosis of rheumatoid arthritis can be established. NSAIDs have not been shown to slow the progression of the disease; therefore, in long-term care, NSAIDs should be used together with
DMARDs 11. Although both these classes of medications are well tolerated for short periods, long term administration may result in gastrointestinal ulcer, perforation, and hemorrhage. Every year 1.5 percent of patients with rheumatoid arthritis are hospitalized with gastrointestinal problems ${ }^{13}$. The risk of these complications increases with older age, corticosteroid use, and a history of peptic ulcer disease.

Recently cyclooxygenase-2 (COX-2) inhibitors, which decrease the incidence of gastric and duodenal ulcers by approximately 50 percent as compared with traditional NSAIDs, have been introduced $^{14,15}$. To a similar degree, the addition of proton-pump inhibitors to therapy with NSAIDs also decreases the incidence of bleeding ulcers associated with traditional NSAIDs ${ }^{15}$. The efficacy of the COX-2 inhibitors is no better than of the older and less expensive NSAIDs ${ }^{14}$. Both traditional NSAIDs and COX-2 inhibitors have associated with increased fluid retention, exacerbation of hypertension, and impairment of renal function in susceptible patients ${ }^{14}$. Thrombotic events have been reported in patients who are taking COX-2 inhibitors and may occur more frequently than with traditional NSAIDs ${ }^{16 .}$

Corticosteroids

Corticosteroids are potent suppressors of the inflammatory response in rheumatoid arthritis and in

Table-I

American College of Rheumatology preliminary Definition of 20 percent Improvement in Rheumatoid Arthritis (ACR 20).

\begin{tabular}{ll} 
Measure of Disease Activity & $\begin{array}{l}\text { Requirement } \\
\text { Tender-joint count }\end{array}$ \\
$\begin{array}{l}\text { Swollen- joint count } \\
\text { Patient's assessment of pain }\end{array}$ & $>20 \%$ Improvement \\
$\begin{array}{l}\text { Patient's global assessment of disease activity } \\
\text { Physician's global assessment of disease activity } \\
\text { Patient's assessment of physical function } \\
\text { Markers of inflammation }\end{array}$ & $>20 \%$ Improvement in \\
& $\begin{array}{l}\text { three of the five } \\
\text { measures }\end{array}$ \\
\hline
\end{tabular}


many other diseases. Unfortunately, their dosedependent side effects are familiar to all clinicians.

Studies conducted more recently 17,18 have corroborated findings from older trials by clearly establishing that corticosteroids decrease the progression of rheumatoid arthritis as detected radio graphically. Corticosteroids in low doses (e.g. $<10 \mathrm{mg}$ of prednisone per day) are used to treat 30 to 60 percent of patients ${ }^{17}$. Table II presents some useful guidelines for corticosteroid use in patients with rheumatoid arthritis. Predictable side effects of corticosteroid drugs include thinning of the skin, cataracts, osteoporosis, hypertension, and hyperlipidemia ${ }^{18}$. The latter three conditions may be preventable with aggressive management of osteoporosis and cardiovascular risk factors. Essentially, all patients taking corticosteroids should receive supplemental calcium (1to $1.5 \mathrm{~g}$ per day) and vitamin D (800 IU per day) ${ }^{19}$. Bisphosphonates appear to be very effective in reducing vertebral fractures is patients taking corticosteroids ${ }^{19}$ (offering a reported 70 percent reduction in incidence) and should be prescribed for patients who have low bone density (e.g. a $\mathrm{T}$ score of -2 or lower). Recent evidence suggests that inflammation plays a major role in atherosclerosis ${ }^{20}$; the ability of corticosteroids to decrease inflammation rapidly may offset some of the potentially detrimental effects of the drugs on the vascular endothelium ${ }^{20}$.

\section{Synthetic Dmards}

Optimal management of rheumatoid arthritis requires rapid and sustained suppression

of inflammation with DMARDs, which are defined as medications that retard or halt the progression of disease. Disease modification is most convincingly demonstrated by the ability of the medications to decrease radiographic progression. A metaanalysis of blinded clinical trials has suggested that the relative efficacy of methotrexate, sulfasalazine, intramusculat gold and penicillamine is similar ${ }^{21}$. Antimalarial drugs (e.g. chloroquine and hydroxychloroquine) are less effective. Penicillamine, because of concern about its toxicity, and oral gold, because of its marginal efficacy are rarely used today ${ }^{21 .}$

Table-II

Keys to Optimizing the Outcome of Treatment

Make an early diagnosis

Start DMARD therapy as early as possible (within three months after onset of symptoms)

Strive for remission (no joint symptoms) in all patients Use corticosteroids as bridge to effective DMARD therapy

Prednisone at doses $>10 \mathrm{mg} /$ day is rarely indicated for joint disease

Avoid using corticosteroids without DMARDs

Minimize duration and dose by tapering to the lowest dose that controls the disease

Always consider prophylaxis to avert osteoporosis

Recognize and treat coexisting illnesses

Facilitate communication between primary care physician and rheumatologist

Since observational trials have clearly identified methotrexate as the synthetic DMARD that is most likely to induce a long-term response, it is most often selected for initial therapy ${ }^{21}$. It has demonstrated efficacy and durability, a long-term track record of acceptable toxicity, and low $\operatorname{cost}^{22}$. An important observational study has shown that patients with rheumatoid arthritis who have been treated with methotrexate have significantly lower mortality (odds ratio for death, 0.4) than patients who have not been treated with methotrexate 23 . Due to its marked efficacy, safety, tolerability and sustainable effect, most clinical trials have listed active disease despite methotrexate therapy as an inclusion criterion and have tested the safety and efficacy of new drugs in comparison with methotrexate 22 . Concomitant administration of folic acid (1 to $3 \mathrm{mg}$ per day) or folinic acid (2.5 to $5 \mathrm{mg}$ given 12 to 24 hours after methotrexate) significantly decreases many toxic effects without a measurable decrease in efficacy and has improved the tolerability of methotrexate ${ }^{24}$, a 
finding that has permitted clinicians to administer 20 to $30 \mathrm{mg}$ of methotrexate per week when necessary. Most data suggest that methotrexate is most effective at a dose of 7.5 to $30 \mathrm{mg}$ per week ${ }^{25}$ but that oral adsorption may be highly variable. Therefore, if oral methotrexate produces a suboptimal response, a trial of subcutaneous or intramuscular methotrexate is indicated ${ }^{11 .}$

Leflunomide, a new synthetic DMARD, has an efficacy similar to that of sulfasalazine or moderate dose methotrexate ${ }^{26,27}$. Leflunomide is given orally as a loading dose of $100 \mathrm{mg}$ daily for 3 days followed by a daily dose of $20 \mathrm{mg}$. Leflunomide is an alternative to MTX as a first-line DMARD in patients intolerant of MTX or with renal insufficiency.

Hydroxychloroquine (200-400 mg/day), considered the least potent but best tolerated of the DMARDs 21 is the DMARD that is most commonly combined with methotrexate. Hydroxychloroquine may be used by itself in an early and mild RA. Sulfasalazine was the first DMARD that was developed specifically to treat rheumatoid arthritis and has an efficacy similar to that of methotrexate ${ }^{21}$. It is often a first-choice agent for rheumatoid arthritis; starting with one tablet $(500 \mathrm{mg})$ daily and building up to the full dose of 2-3 gm daily over two weeks. Sulfasalazine is most commonly used in the United States as part of combination DMARD therapy ${ }^{21 .}$ Intramuscular gold $(500 \mathrm{mg} / \mathrm{month})$ provide significant clinical improvement in up to $30 \%$ of patients with rheumatoid arthritis and prolonged complete remission have been observed ${ }^{28}$. Its cumbersome administration and toxicity have limited its use $^{21}$.Safe administration of DMARDs requires critical and careful monitoring (table III) 29. Detailed monitoring guidelines have been published to help avert damage to the liver ${ }^{30}$, which was a major concern when use of the drug for rheumatoid arthritis became popular in the mid1980s. These guidelines include measuring serum albumin and aminotransferase levels every four to eight weeks. Doses of methotrexate should be decreased when aminotransterase levels ate elevated above the upper limit of normal, and treatment should be stopped if the elevation persists. Obtaining complete blood counts and measuring serum creatinine are also recommended ${ }^{29}$, since a decrease in renal function may precipitate toxic effects in a patient in previously stable condition who is taking methotrexate.

Both methotrexate and leflunomide have a substantial potential for teratogenesis ${ }^{30}$. So women of childbearing potential who require these medications should be using reliable birth control. Subacute pneumonitis is rare with methotrexate (51 cases have been reported worldwide) but may be life-threatening ${ }^{32}$. If pneumonitis is suspected on the basis of clinical findings or a chest radiograph, methortexate should be promptly discontinued and not reintroduced. As the best tolerated of all the DMARDs, hydroxychloroquine is used at doses below $6.5 \mathrm{mg}$ per kilogram of lean body mass per day, requires only yearly visits to the opththalmologist to prevent the rare occurrence of retinal toxic effects ${ }^{33}$.

Four double blind, controlled trials have now shown that minocycline is effective in treating rheumatoid arthritis ${ }^{34}$, 35. Minocycline that was used as initial therapy in patients who tested positive for rheumatoid factor was superior to placebo (response rate 65 percent, as compared with 13 percent for placebo $)^{34}$ and superior to hydroxy-chloroquine (60 percent vs. 33 percent $)^{35}$ when measuring ACR 50. The mechanism by which minocycline works is incompletely understood but probably involves innunomodulation, suppression of matrix metalloproteinases and suppression of nonspecific infections that would otherwise stimulate inflammatory cytokine production ${ }^{35}$. Reversible hyper pigmentation is seen in up to 30 percent of patients who are receiving long-term minocycline therapy. 


\section{Biologic DMARDS}

Table-III

Guidelines for Monitoring the Traatment of Rheumatoid Arthritis

\begin{tabular}{|c|c|c|c|c|c|}
\hline Drug & Potential Toxic Effects & Baseline Evaluation & System Review or Examination & Laboratory Tests & Coments \\
\hline $\begin{array}{l}\text { Hydroxychlor- } \\
\text { oquine }\end{array}$ & Macular changes & $\begin{array}{l}\text { None unless patient is }>40 \text { years } \\
\text { old or has previous eye problems }\end{array}$ & $\begin{array}{l}\text { Visualchanges'check funduscopic and } \\
\text { visual fields every year }\end{array}$ & None & Best tolerated DMARD \\
\hline Methotrexate & $\begin{array}{l}\text { Myelosuppression, hepatic fibrosis, } \\
\text { pneumonitis }\end{array}$ & $\begin{array}{l}\mathrm{CBC}, \quad \text { recent chest } \\
\text { radiograph,ALT, creatinine, and } \\
\text { albumin, hepatitis } \mathrm{B} \text { and } \mathrm{C} \\
\text { serology }\end{array}$ & $\begin{array}{l}\text { Mouth ulcers, short-ness of breath, new- } \\
\text { onset cough, nausea }\end{array}$ & $\begin{array}{l}\mathrm{CBC} \text {, ALT, albumin every } 4-8 \\
\text { weeks }\end{array}$ & $\begin{array}{l}\text { Pregnancy contraindicated; } \\
\text { patients must avoid alcohol }\end{array}$ \\
\hline Leflunomide & Myelosuppression, hepatic fibrosis & $\begin{array}{l}\mathrm{CBC} \text {, ALT, albumin, hepatitis B } \\
\text { and } \mathrm{C} \text { serology }\end{array}$ & $\begin{array}{l}\text { Diarrhea, weight loss, elevated blood } \\
\text { pressure }\end{array}$ & $\begin{array}{l}\text { CBC, ALT, albumin every } 4-8 \\
\text { weeks }\end{array}$ & $\begin{array}{l}\text { Long half-life; pregnancy } \\
\text { contraindicated; patients should } \\
\text { limit alcohol intake }\end{array}$ \\
\hline $\begin{array}{l}\text { Gold } \\
\text { (intramuscular) }\end{array}$ & $\begin{array}{l}\text { Myelosuppression, } \\
\text { Proteinuria }\end{array}$ & $\begin{array}{l}\mathrm{CBC} \text {, creatinine, urine dipstick } \\
\text { for protein }\end{array}$ & Rash, mouth ulcers fever, bruising, pallor & $\mathrm{CBC}$ and dipstick & \\
\hline Cyclosporine & $\begin{array}{l}\text { Renal insufficiency, anemia, hyper- } \\
\text { tension }\end{array}$ & $\begin{array}{l}\text { Screen for } \\
\text { previous tuberculosis }\end{array}$ & Edema; check blood pressure monthly & $\begin{array}{l}\text { Creatinine every } 2 \text { weeks until } \\
\text { stable dose, then every month; } \\
\text { CBC every } 3 \text { months }\end{array}$ & Poor long-term continuation rates \\
\hline Etanercept & Infections & $\begin{array}{l}\text { Screen for } \\
\text { previous tuberculosis }\end{array}$ & $\begin{array}{l}\text { Infections; symptoms of CHF or demye- } \\
\text { linating disease }\end{array}$ & $\begin{array}{l}\text { None unless patient also receiving } \\
\text { other DMARDs }\end{array}$ & $\begin{array}{l}\text { Discontinue } \\
\text { during infections }\end{array}$ \\
\hline Infliximab & Infections & $\begin{array}{l}\text { Screen for } \\
\text { previous tuberculosis }\end{array}$ & $\begin{array}{l}\text { Infections; symptoms of CHFor demye- } \\
\text { linating disease }\end{array}$ & $\begin{array}{l}\text { None unless patient also receiving } \\
\text { other DMARDs }\end{array}$ & $\begin{array}{l}\text { Discontinue } \\
\text { during infections }\end{array}$ \\
\hline Adalimumab & Infections & $\begin{array}{l}\text { Screen for } \\
\text { previous tuberculosis }\end{array}$ & $\begin{array}{l}\text { Infections; symptoms of CHF or demye- } \\
\text { linating disease }\end{array}$ & $\begin{array}{l}\text { None unless patient also receiving } \\
\text { other DMARDs }\end{array}$ & $\begin{array}{l}\text { Discontinue } \\
\text { during infections }\end{array}$ \\
\hline
\end{tabular}

Three biologic products that inhibit the actions of TNF- $\alpha$ (infliximab, etanercept, and adalimumab), one that inhibits the action of interleukin-1 (anakinra) and an anti CD20 monoclonal antibody are now available to treat rheumatoid 36. Infliximab is a chimeric human-murine anti TNF- $\alpha$ monoclonal antibody, which is administered by intravenous infusion, $3 \mathrm{mg} / \mathrm{kg}$ at 0,2 and 6 weeks and then every 1-2 month. Etanercept is a synthetic human TNF receptor-Fc protein, administered subcutaneously $25 \mathrm{mg}$ twice weekly or $50 \mathrm{mg}$ weekly. Adalimumab is a human monoclonal antibody to TNF- $\alpha$ administered subcutaneously $40 \mathrm{mg}$ every 1-2 week. Anakinra, a recombinant form of human interleukin-1 receptor antagonist, $100 \mathrm{mg}$ daily by subcutaneous injection may be useful in patients who have no response to or unable to tolerate methotrexate, leflunomide or TNF$\alpha$ antagonist.

Rituximab is a chimeric (humanized mouse) anti CD20 monoclonal antibody that depletes CD20 positive $\mathrm{B}$ cells. It has been approved by the FDA in 2006 and has demonstrated clinical efficacy and safety in of rheumatoid arthritis with incomplete response to methotrexate.In a randomized, double-blind controlled clinical study of 161 patients who had active rheumatoid arthritis despite methotrexate treatment, a single course of two infusions of rituximab $(1000 \mathrm{mg}$ on days 1 and 15) alone or in combination with either cyclophosphamide(750 mg on days 3 and 17) or continued methotrexate $(\geq 10 \mathrm{mg} /$ week $)$,provided significant improvement in disease symptoms at both weeks 24 and $48 .{ }^{42}$ 
These drugs are more effective than standard DMARDs (with faster onset of action, greater clinical efficacy and sustained benefit) but because of their cost many countries have set restrictive guidelines for their use. Current UK recommendations are that they should be initiated only in active RA when an adequate trial of at least two other DMARDs (including methotrexate) has failed.

\section{Combination Therapy with DMARDS}

One of the first randomized studies that directly compared combination DMARD therapy with methotrexate was a two-year, double-blind trial in which patients were assigned to three groups: those who took methotrexate alone (at $17.5 \mathrm{mg}$ per week), those who took a combination of sulfasalazine (at 1 g per day) and hydroxychloroquine (at $400 \mathrm{mg}$ per day), and those who took all three medications ${ }^{37}$. At two years, the end point of 50 percent improvement in composite symptoms of arthritis was reached by 77 percent of patients who were treated with all three drugs but by only 33 percent of patients who were treated with methotrexate alone. Patients who received combination therapy did not have more side effects than those who received methotrexate alone. In another study, the triple combination of methotrexate (at $17.5 \mathrm{mg}$ per week), sulfasalazine (at $2 \mathrm{~g}$ per day), and hydroxy-chloroquine (at $400 \mathrm{mg}$ per day) was superior to either the combination of methotrexate and sulfasalazine or the combination of methotrexate and hydroxychloroquine ${ }^{38}$.

In patients who have early disease, three critical trials have all shown that initial combination therapy is superior to therapy with a single DMARD ${ }^{39}, 40$. The Combination therapy Bij Rheumatoid Arthritis $(\mathrm{COBRA})^{39}$ trial compared sulfasalazine alone with the combination of sulfasalazine, low-dose methotrexate (which was stopped at 40 weeks), and predinisolone (which was given initially at $60 \mathrm{mg}$ per day but tapered off by 28 weeks). Patients in the combination group had a more rapid response to treatment, fewer withdrawals from the study because of toxicity, and most important, less radiographic evidence of progression at five years ${ }^{41}$. Other trials involving patients with early disease have demonstrated the superiority of triple therapy (methotrexate, sulfasalazine, and hydroxychloroquine) over sulfasalazine alone ${ }^{40}$, double therapy (methotrexate and sulfasalazine or methotrexate and hydroxychloroquine), and monotherapy ${ }^{42}$.

\section{Initial Treatment}

Establishing a diagnosis as early as possible and then starting DMARD therapy is the foundation for successful treatment of patients with rheumatoid arthritis. Most rheumatologists select methotrexate as the initial therapy for most patients ${ }^{43}$. The characteristics and personal choices of patients influence this decision ${ }^{11}$. Methotrexate should not be used in patients who have underlying liver or renal disease, who consume alcohol, who plan to become pregnant in the near future, or who do not want to undergo regular laboratory monitoring. Whether to start a course of low-dose corticosteroids initially along with the chosen DMARD is controversial, many clinicians start treatment with prednisone at 5 to $7.5 \mathrm{mg}$ per day as bridge therapy until the sloweracting DMARDs have a chance to work. Once the DMARD begins working, corticosteroids should be tapered (Table-II).

Methotrexate is started at a dose of $10 \mathrm{mg}$, given orally once weekly. If patients continue to have active disease (as indicated by swollen and tender joints), as most do, the dose should be increased in $5 \mathrm{mg}$ increments after two weeks interval up to $30 \mathrm{mg}$ per week. If patients continue to have active disease, consideration should be given to switching to subcutaneous administration of equivalent dose of methotrexate ${ }^{11}$. If active disease persists despite optimal methotrexate therapy for 2-3 months, other DMARDs should be added ${ }^{21}$. The Early Rheumatoid Arthritis (ERA) trial ${ }^{44}$ is an important study that compared methotrexate (at a dose that escalated to 20 mg per week) with etanercept in patients with disease diagnosed within the preceding three years. Both treatments were very effective in controlling the disease at one year, but etanercept (administered at 25 mg subcutaneously twice a week) was more effective in rapidly suppressing disease activity. In both the ERA and COBRA trials, markers of inflammation (including the erythrocyte sedimentation rate and the C-reactive protein level) were dramatically reduced after two weeks of therapy. If, in fact, it is important to control disease in days, rather than in weeks or months, then corticosteroids and TNF inhibitors (both 
of which appear to be capable of stopping active disease) should be examined in trials to test the concept of induction therapy (i.e., medication that is administered initially and then withdrawn).

\section{Therapy for Established Rheumatoid Arthritis}

If patients continue to have active disease after two to three months of methotrexate at a dose of 20 to $30 \mathrm{mg}$ per week, or if they cannot tolerate higher doses of methotrexate despite folate replacement, the current standard practice is to add another DMARD to methotrexate $^{11}$. The most economical initial choice ${ }^{44}$ for the patient who has active disease despite taking methotrexate is the addition of sulfasalazine, hydroxychloroquine, or both. If active disease (manifested by swollen and tender joints) persists after three months of these DMARD combinations, leflunomide or a TNF inhibitor should be added to methotrexate.

If DMARD therapy is started within three months after the onset of symptoms and escalated with the goal of achieving remission, the majority of patients will have their disease well controlled within a year while taking conventional single or combination DMARD therapy ${ }^{45}$.If inflammatory disease is inadequately controlled, therapy with TNF inhibitors should be started.

\section{Coexisting Illnesses}

The long-term prognosis for patients with rheumatoid arthritis depends not only on how well their joint disease is treated but also on how well their coexisting illnesses are addressed ${ }^{46}$. The three coexisting conditions that have the greatest effect on morbidity and mortality in rheumatoid arthritis are infection (particularly pulmonary infection), osteoporosis, and cardiovascular disease.

Rheumatoid arthritis is associated with approximately a doubling of the risk of infection, as compared with the risk in age-matched controls ${ }^{47}$, and the degree of increase in the risk correlates with the severity of the disease $^{48}$. Although some studies suggest that corticosteroids may increase the risk of infection ${ }^{49}$, controversy exists about whether such an increase is due to the use of corticosteroids itself or to the fact that patients who are at higher risk are more likely to use corticosteroids. Whether the new TNF inhibitors increase the risk of infection is a matter for debate since the drugs have been associated with a change in the spectrum of infections ${ }^{50}$ specifically, increase tuberculosis, histoplasmosis, and listeria. ${ }^{6}$

The clinician who is caring for patients with rheumatoid arthritis should be aware of the risk of infection. All patients should have yearly influenza vaccinations and should receive the pneumococcal vaccine at appropriate intervals. Since patients may have a better immunologic response to vaccination before taking methotrexate ${ }^{51}$, it seems prudent to vaccinate before starting DMARD treatment, when possible. Live vaccines should be avoided in patients who are receiving immunosuppressive medications. When considering TNF inhibitors, clinicians should recommend that all patients be tested for prior exposure to tuberculosis. Both clinicians and patients with rheumatoid arthritis should be vigilant with regard to avoiding infections and treating them early and aggressively. Stopping or withdrawing drug treatment during infections is critical ${ }^{50}$

The incidence of osteoporosis is doubled in patients with rheumatoid arthritis ${ }^{52}$ and baseline bone-density studies should be performed in all patients, particularly those who will receive corticosteroids. If osteoporosis is present, bisphosphonate therapy, which is reported to decrease the risk of fracture by 70 percent despite the co administration of corticosteroids should be used ${ }^{19}$.

Cardiovascular disease accounts for most of the excess mortality associated with rheumatoid disease $^{20}$. The newer concepts of the pathogenesis of atherosclerosis suggest that inflammation is a key factor in causing vascular endothelial damage ${ }^{20}$. It has been hypothesized that the systemic inflammation that characterizes rheumatoid arthritis may play a key role in the excess artherosclerosis seen in patients with this disease ${ }^{20}$. Risk factors for atherosclerosis should be aggressively soughted and addressed. In particular, smoking cessation may be fruitful, since smoking has been associated with increased severity of arthritis ${ }^{53}$. Current trials of statin therapy in patients with rheumatoid arthritis may address the risk of cardiovascular disease, since statins should decrease atherosclerosis and inflammation ${ }^{54}$.

Many of the new therapies are expensive, with initial costs that may exceed $\$ 1,500$ per month. However, 
these upfront costs may be justified in the long term by savings that result from an improved quality of life and enhanced productivity.

The treatment of rheumatoid arthritis has improved dramatically in the past decade ${ }^{7,8}$. Thanks to early diagnosis and the availability of DMARDs. Physicians can now have the goal of eradicating active disease and aggressively intervening to address coexisting illnesses. Remission in patients who are receiving therapy is now a realistic goal.

\section{Summary and Conclusion:}

The treatment of rheumatoid arthritis has changed dramatically in the past decade due to improved understanding of its pathophysiology and the availability of DMARDS. Initiation of treatment very early in the disease (within three months), the use of combinations of DMARDs and emergences of a number of new drugs (TNF- $\alpha$ antagonists, IL-1 antagonist, anti CD20 antibody) that have novel mechanism of action have made it possible to achieve control of synovitis and improvement in the quality of life in the majority of rheumatoid arthritis patients. Many of the new therapy are expensive, with initial costs that may exceed $£ 1500$ per month. However, these upfront costs may be justified in the long term by savings that results from an improved quality of life and enhanced productivity. Indeed, emerging clinical and epidemiological data suggest that excellent long term control of synovitis will result in significant reduction in rate of unemployment, joint surgeries, disability and mortality in rheumatoid arthritis patients. Complete remission of disease (on therapy) should be the goal of treatment, even if not achievable, in all RA patients

\section{Reference:}

1. Scott DL, Symmons DPM, Coulton BL, Popert AJ. Longterm outcome of treating rheumatoid arthritis: results after 20 years. Lancet 1987; 1:1108-11.

2. Gabriel SE. The epidemiology of rheumatoid arthritis Rheum Dis Clin North Am 2001; 27: 269-81.

3. Symmons DP, Barrett EM, Bankhead CR, Scoott DG, Silman AJ. The incidence of rheumatoid arthritis in the United Kingdom: Results from the Norfolk Arthritis Register. Br.J Rheumatol 1994; 33; 735-9.

4. Choy EHS, Panayi GS. Cytokine pathways and joint inflammation in rheumatoid arthritis. N Engl J Med 2001; 344:907-16
5. Van der Heijde DM. Joint erosions and patients with early rheumatoid arthritis. Br J Rheumatol 1995; 34Suppl 2:74

6. Lard LR, Visser H, Speyer I. Early versus delayed treatment in patients with recent onset rheumatoid arthritis: comparison of two cohorts who received different treatment strategies. AM J Med 2001; 11:445-51.

7. O'Dell JR. Treating rheumatoid arthritis early: a window of opportunity. Arthritis Rheum 2002; 46:283-5.

8. Arnett FC, Edworthy SM, Bloch DA, Mc Shane DJ, Fries JF, Cooper NS et al. The American Rheumatism Association 1988 revised criteria for the classification of rheumatoid arthritis. Arthritis Rheum 1988; 31:315-24.

9. Jansen ALMA, van der Horst-Bruinsma IE, van Schaardenburg D, van de Stadt RJ, de Koning MHMT, Bijkmans BAC. Rheumatoid factor and antibodies to cyclic citrucllinated peptide differentiate rheumatoid arthritis from undifferentiated polyarthritis in patients with early arthritis. J Rheumatol 2002; 29:2074-6.

10. Nielen MM, van Schaardenburg D, Reesink HW. Specific auto antibodies precede the symptoms of rheumatoid arthritis: a study of serial measurements in blood donors. Arthritis Rheum 2004, 50,380-6.

11. American College of Rheumatology Sub-committee on Rheumatoid Arthritis Guidelines. Guidelines for the management of rheumatoid arthritis: 2002 update. Arthritis Rheum 2002; 46:328-42.

12. Felson DT, Anderson JJ, Boers M. Preliminary definition of improvement in rheumatoid arthritis. Arthritis Rheum 1995;38:727-35.

13. Singh G. Recent considerations in non-steroidal antiinflammatory drug gastropathy. Am J Med 1998; 105: Suppl 1B: $31 \mathrm{~S}-38 \mathrm{~S}$

14. Silverstein FE, Faich G, Goldstein. Gastrointestinal toxicity with celecoxib vs nosteroidal anti-inflammatory drugs for osteoarthritis and rheumatoid arthritis: the CLASS study: a randomized controlled trial. JAMA 2000:284:1247-55.

15. Chan FKI, Hung LCT, Suen BY. Celecoxib versus diclofenac and omeprazole in reducing the risk of recurrent ulcer bleeding in patients with arthritis. N Engl J Med 2002; 347:2104-10

16. Stand V, Hochberg MC. The risk of cardiovascular thrombosis events with selective cyclooxygenase-2 inhibitors. Arthritis Rheum 2002; 47:349-55.

17. Kirwan JR, Arthritis and Rheumatism Council Low-Dose Glucocorticoids on joint destruction in rheumatoid arthritis. N Engl J Med 1995; 333:142-6.

18. Van Everdingen AA, Jacobs JWG, Siewertsz van Resema DR, Bijlsma WJ. Low dose prednisone therapy for patients with early active rheumatoid arthritis; clinical efficacy, disease-modifying properties, and side effects: a randomized, double blind, placebo-controlled clinical trial. Ann Intern Med 2002; 135:1-12. 
19. American College of Rheumatology Ad Hoc Committee on Glucocorticoid-Induced Osteoporosis. Recommendations for the prevention and treatment of Glucocorticoid induced osteoporosis: 2001 update. Arthritis Rheum 2001; 44:1496503.

20. Van Doorrnum S, McColl G, Wicks IP. Accelerated atherosclerosis: an extraarticular feature of rheumatoid arthritis? Arthritis Rheum 2002; 46:862-73.

21. Felson DT, Anderson JJ, Meenan RF. The comparative efficacy and toxicity of second-line drugs in rheumatoid arthritis; results of two metaanlyses. Arthritis Rheum 1990; 33:1449-61.

22. Ortendahl M, Holmes T, Schettler JD, Fries JF. The methotrexate therapeutic response in rheumatoid arthritis. J Rheumatol 2002; 29:2084-91.

23. Choi HK, Hernán MA, Seeger JD, Robins JM, Wolfe F. Methotrexate and mortality in patients with rheumatoid arthritis: a prospective study. Lancet 2002; 359:1173-7.

24. Van Ede AE, Laan RF, Rood MJ. Effect of folic or folinic acid supplementation on the toxicity and efficacy of methotrexate in rheumatoid arthritis: a forty-eight week, multiceneter, randomized, doubleblind, placebo-controlled study. Arthritis Rheum 2001; 44:1515-24.

25. Genovese M, Keystone EC, Tesser JRP, Finck BK, SpencerGreen GT. High dose oral methotrexate (MTX) in early RA is needed for maximum efficacy. Arthritis Rheum 2000; 43 Suppl: S382.abstract.

26. Smolen JS, Kalden JR, Scott DL. Efficacy and safety of leflunomide compared with placebo and sulphasalzine in active rheumatoid arthritis: a double-blind randomized multicentre trial. Lancet 1999; 353:259-66.

27. Strand V, Cohen S, Schiff M. Treatment of active rheumatoid arthritis with leflunomide compared with placebo and methotrexate. Arch Intern Med 1999 $159: 2542-250$

28. Rau R, Herborn G, Menninger H, Blechschmidt J Comparison of intramuscular methotrexate and gold sodium thiomalate in the treatment of early erosive rheumatoid arthritis: 12 month data of double-blind parallel study of 174 patients. Br J Rheumatol 1997; 36:345-52.

29. American College of Rheumatology Adhoc Committee on Clinical Guidelines. Guidelines for monitoring drug therapy in rheumatoid arthritis. Arthritis Rheum 1995; 39:723-31.

30. Kremer JM, Alarcon GS, Lightfoot RW Jr. Methotrexate for rheumatoid arthritis: suggested guidelines for monitoring liver toxicity. Arthritis Rheum 1994; 37:316-28.

31. Janssen NM, Genta MS. The effects of immunosuppressive and anti-inflammatory medications on fertility, pregnancy, and lactation. Arch Intern Med 2000; 160:610-9.

32. Kremer JM, Alarcon GS, Weinblatt ME. Clinical, laboratory, radiographic, and histopathologic features of methotrexate- associated lung injury in patients with rheumatoid arthritis: a multicenter study with literature review. Arthritis Rheum 1997; 40:1829-37.

33. Marmor MF, Carr RE, Easterbrook M, Farjo AA, Mieler WF. Recommendations on screening for chloroquine and hydroxy-chloroquine retinopathy: a report by the American Academy of Ophthalmology. Ophthalmology 2002; 109:1377-82

34. Kloppenburg M, Breedveld FC, Terwiel JP, Mallee C, Kijkmans B.A. Minocycline in active rheumatoid arthritis: a double blind, placebo-controlled trial. Arthritis Rheum 1994; 37:629-36

35. O'Dell JR, Blakely KW, Mallek. Treatment of early seropositive rheumatoid arthritis: a two-year, double-blind comparison of minocycline and hydroxychloroquine, Arthritis Rheum 2001; 44:2235-41

36. Olsen NJ, Stein CM. New drugs for rheumatoid arthritis. N Engl J Med 2004; 350:2167-79

37. O'Dell JR, Haire CE, Erikson N. Treatment of rheumatoid arthritis with methotrexate alone, sulfasalazine and hydroxychloropuine, or combination of all three medications. N Engl J Med 1996; 334:1287-91.

38. O'Dell JR, Leff R, Paulsen G. Treatment of rheumatoid arthritis with methotrexate and hydroxychloropuine, methotrexate and sulfasalazine, or a combination of the three medications: results of a two year, randomized, double blind, and placebocotrolled trial. Arthritis Rheum 2002; 46:1164-70.

39. Boers M, Verhoeven AC, Markusse HM. Randomized comparison of combined step-down prednisolone, methotrexate and sulphasalazine with sulphasalazine alone in early rheumatoid arthritis. Lancet 1997; 350:309-18. [Erratum, Lancet 1998; 351:220.]

40. Mottonen T, Hannonen P, Leirisalo- Repo M. Comparison of combination therapy with single-drug therapy in early rheumatoid arthritis: a randomized trial. Lancet 1999; 3531568-73.

41. Landewe RBM, Boers M, Verhoever AC, Westhovens R, Vande Laar MA, Murkusse HM et al. COBRA combination therapy in patients with early rheumatoid arthritis:longterm structural benefits of a brief intervention. Arthritis Rheum 2002; 46:347-56.

42. Edwards JCW, Szczepanski L, Szechin ski J, Sosnowska AF, Emery P, Close DR et al. Efficacy of B-cell-targeted therapy with rituoximab in patients with rheumatoid arthritis. N Engl J Med 2004; 350:2572-81.

43. Mikuls TR, O'Dell JR. The changing face of rheumatoid arthritis therapy: results of serial surveys. Arthritis Rheum 2002; 43: 464-5.

44. Bathon JM,Martin RW,Fleichmann RM. A comparison of etanercept and methotrexate in patients with early rheumatoid arthritis. N Engl J Med 2000; 343:1586-1593. 
45. Sokka T, Pincus T. Eligibility of patients in routine care for major clinical trials of anti-tumour necrosis factor alpha agents in rheumatoid arthritis. Arthritis Rheum 2003;48:313-8

46. Mikuls TR, Saag KG. Comorbidity in rheumatoid arthritis Rheum Dis Clin North AM 2001; 27: :283-303.

47. Doran MF, Crowson CS, Pond GR, O'Fallon WM, Gabriel SE. Frequency of infection in patients with rheumatoid arthritis compared with controls: a population-based study. Arthritis Rheum 2002; 46:2287-93.

48. Wolfe F, Mitchell DM, Sibley JT. The mortality of rheumatoid arthritis. Arthritis Rheum 1994; 37:481-94.

49. Doran MF, Crowson CS, Pond GR, O’ Fallon WM, Gabriel SE. Predictors of infection in rheumatoid arthritis. Arthritis Rheum 2002; 46:2294-300

50. Ellerin T, Rubin RH, Weinblatt ME. Infections and antitumor necrosis factor $\alpha$ therapy. Arthritis Rheum 2003:48:3013-22.
51. O’Dell JR. Gilg J, Palmer W, Haire C, Klassen L, Moore G. Pneumococcal vaccine in rheumatoid arthritis: decreased response while taking methotrexate. J Clin Rheumatol 1996; 2:59-63.

52. Haugeberg G, Orstavik Re, Uhlig T, Falch JA, Halse JI, Kvien TK. Bone loss in patients with rheumatoid arthritis: results from a populations-based cohort of 366 patients followed up for two years. Arthritis Rheum 2002; 46:17208.

53. Mattey DL, Hutchinson D, Dawes PT. Smoking and disease severity in rheumatoid arthritis: association with polymorphism at the glutathione S-transferase M 1 locus. Arthritis Rheum 2002; 46:640-6.

54. Leung BP, Sattar N, Crilly A. A novel anti-inflammatory role for simvastatin in inflammatory arthritis. J Immunol 2003; 170: 1524-30. 